\section{Murray-Valley-Enzephalitis-Viren (MVEV)}

W. Stöcker

Euroimmun Medizinische Labordiagnostika AG, Lübeck, Deutschland

Englischer Begriff Murray Valley encephalitis virus

Beschreibung des Erregers Familie: Flaviviridae; Gattung: Falvivirus; Art: Murray-Valley-Enzephalitis-Virus. Plusstrang-RNA-Genom, behüllt, MVEV gehört zum Japanischen-Enzephalitis-Virus-Serokomplex.

Erkrankungen Vorkommen: Australien, Papua-Neuguinea und West-Neuguinea.

Vektoren: Culex annulirostris.

Wirte: Wasservögel (Virusreservoir), Menschen.

Klinik: Es werden 2 Verlaufsformen unterschieden. Milder Verlauf: Kopfschmerzen, Fieber, oft auch Nackensteifigkeit, Übelkeit, Erbrechen, Durchfall. Die Symptome stabilisieren sich innerhalb von etwa 1 Woche. Schwerer Verlauf: Enzephalitis mit Nackensteife, Lichtempfindlichkeit, Krämpfen, Anfällen, Ateminsuffizienz, Lähmungen und Bewusstseinsstörungen, neurologische Spätfolgen (Verhaltensstörungen, Persönlichkeitsveränderungen, Ataxien, Lähmungserscheinungen) bei bis zu $50 \%$ der betroffen Patienten, in 15-30\% der Fälle verläuft die Enzephalitis tödlich.

Etwa 1 unter 1000 infizierten Personen erkrankt schwer, insbesondere Kleinkinder.

Analytik Direktnachweis: Virusisolation oder Nachweis viraler RNA durch RT-PCR (Polymerase-Kettenreaktion).

Serologie: Nachweis spezifischer Antikörper (IgM, IgG) im Serum durch indirekte Immunfluoreszenz ( $\triangleright$ Immunfluoreszenz, indirekte) oder $>$ Enzyme-linked Immunosorbentassay.
Probenmaterial Direktnachweis: Blut oder Liquor. Das Material sollte bis zur Weiterverarbeitung bei +4 bis $+8{ }^{\circ} \mathrm{C}$ aufbewahrt werden.

Serologie: Serum oder Plasma für den Nachweis der Antikörper sind bei $+4{ }^{\circ} \mathrm{C}$ bis zu 2 Wochen lang beständig, bei $-20{ }^{\circ} \mathrm{C}$ über Monate und Jahre hinweg. Zur Tiefkühlkonservierung des IgM kann man den Proben 80 \% gepuffertes Glyzerin beifügen.

Diagnostische Wertigkeit Die Anamnese, insbesondere Informationen über längere Aufenthalte in Endemiegebieten ist wichtig. Der Nachweis spezifischer Antikörper (IgM, IgG) gilt als Standardverfahren der MVEV-Diagnostik. Ein signifikanter Anstieg des IgG-Titers ist ein sicherer Beleg für die Infektion. Mögliche Kreuzreaktivitäten mit Antikörpern gegen andere Flaviviren müssen berücksichtigt werden.

\section{Literatur}

Dobler G, Aspöck H (2010) Durch Stechmücken übertragene Arboviren als Erreger von Infektionen des Menschen. In: Aspöck H (Hrsg) Krank durch Arthroponden, Denisia 30:501-553

Knox J, Cowan RU, Doyle JS, Ligtermoet MK, Archer JS, Burrow JNC, Tong SYC, Currie BJ, Mackenzie JS, Smith DW, Catton M, Moran RJ, Aboltins CA, Richards JS (2012) Murray Valley encephalitis: a review of clinical features, diagnosis and treatment. Med J Aust 196(5):322-326

Selvey LA, Dailey L, Lindsay M, Armstrong P, Tobin S et al (2014) The changing epidemiology of Murray Valley encephalitis in Australia: the 2011 outbreak and a review of the literature. PLoS Negl Trop Dis 8(1):e2656. https://doi.org/10.1371/journal.pntd.0002656 